\title{
Rosiglitazone Influences the Expression of Leukocyte Adhesion Molecules and CD14 Receptor in Type 2 Diabetes Mellitus Patients
}

\author{
T. ŠTULC ${ }^{1}$, H. SVOBODOVÁ ${ }^{1}$, Z. KRUPIČKOVÁ ${ }^{1}$, R. DOLEŽALOVÁ ${ }^{1}$, I. MARINOV ${ }^{2}$, \\ R. С̌E $\check{S K K A}^{1}$
}

${ }^{1}$ Third Department of Internal Medicine, First School of Medicine, Charles University, Prague, Czech Republic, ${ }^{2}$ Institute of Hematology and Blood Transfusion, Prague, Czech Republic

Received March 20, 2014

Accepted March 26, 2014

\begin{abstract}
Summary
Diabetes mellitus is associated with increased inflammatory response, which may contribute to atherosclerosis progression. Experimental results demonstrated anti-inflammatory activity of glitazones; their effect on leukocyte adhesion molecules has not been studied to date. We therefore studied the effect of rosiglitazone treatment on leukocyte surface expression of adhesion molecules in patients with type 2 diabetes mellitus and compared our results with findings in healthy subjects. 33 subjects with type 2 diabetes and 32 healthy controls were included; patients were examined at baseline and after 5 months of rosiglitazone treatment $(4 \mathrm{mg} / \mathrm{d})$. Leukocyte expression of adhesion molecules LFA-1, CD18 and ICAM-1 was quantified using flow cytometry; in addition, CD14 (lipopolysaccharide receptor) expression was analyzed as a marker of nonspecific immunity. The expression of examined molecules at baseline was higher in patients compared to controls. Despite only mild decrease in blood glucose, rosiglitazone treatment induced substantial decrease of CD18 and CD14 expression and borderline decrease of LFA-1 and ICAM-1 expression (on monocytes only). We thus observed improvement in the expression of leukocyte inflammatory markers after rosiglitazone treatment. This effect is supposed to be mediated by direct effect of rosiglitazone on PPAR-y receptors on leukocytes.
\end{abstract}

\section{Key words}

Diabetes mellitus • Rosiglitazone • Cell adhesion molecules • Lipopolysaccharide receptor $\bullet$ Leukocytes

\section{Corresponding author}

T. Štulc, Third Department of Internal Medicine, First School of Medicine, Charles University, U Nemocnice 1, CZ 12821
Prague 2, Czech Republic. Fax: +420-22491 9780. E-mail: tstulc@lf1.cuni.cz

\section{Introduction}

Patients with diabetes mellitus have substantially increased risk of cardiovascular diseases due to premature atherosclerosis. Diabetes is associated with increased inflammatory response involving vessel wall, immune cells and circulating inflammatory molecules, which together contribute to premature atherosclerosis in diabetic patients (Moreno and Fuster 2004, Bansilal et al. 2007).

Leukocyte activation plays an important role in atherosclerosis lesion development. Leukocytes serve as precursors for the formation of foam cells, impair endothelial dysfunction, maintain the inflammatory infiltration of the plaque and influence myointimal proliferation (Huo and Ley 2001). The infiltration of the subendothelial space with leukocytes is mediated by cell adhesion molecules, which are expressed on the surface of leukocytes and endothelial cells (Rosenfeld 2002). Leukocyte recruitment is further enhanced by nonspecific proinflammatory stimuli, acting through receptors involved in innate immunity. A key molecule among these is monocyte antigen CD14, which is a principal part of lipopolysaccharide receptor complex (Palsson-McDermott and O'Neill 2004).

Various proatherogenic factors, including hyperglycemia, up-regulate the expression of cell adhesion molecules (Caimi et al. 2003, Kostidou et al. 2009), and increased expression of CD14 in patients with 
diabetes was reported in two studies (Fogelstrand et al. 2004, Stulc et al. 2012). However, the effect of glucose lowering treatment on leukocyte activation markers has not been studied to date. We therefore studied the effect of the PPAR- $\gamma$ agonist, rosiglitazone, on leukocyte expression of several adhesion molecules and lipopolysaccharide (CD14) receptor in patients with type 2 diabetes mellitus.

\section{Methods}

We included patients with type 2 diabetes mellitus, which was not properly controlled by monotherapy with metformin ( $94 \%$ of patients) or sulfonylurea derivatives ( $6 \%$ of patients). Patients taking combination of antidiabetic drugs or insulin, as well as those with severe uncontrolled hypertension (blood pressure $>160 / 100$ torr), renal insufficiency (serum creatinine $>150 \mu \mathrm{mol} / \mathrm{l}$ ), uncontrolled hypothyroidism, current infection or malignancy were excluded. Antihypertensive and lipid-lowering therapy was not changed during the study. The control group consisted of healthy non-diabetic subjects without manifest vascular disease. Patients with diabetes were treated with rosiglitazone $4 \mathrm{mg}$ once daily for 5 months. Clinical and laboratory examinations were performed at baseline and at the end of the treatment period; in the control group, only baseline examination was performed. All subjects signed an informed consent; the study protocol was approved by the Local Ethics Committee.

Blood for laboratory tests was drawn after an overnight fast. Measurements of leukocyte surface molecules were performed within 2 hours of blood sampling. Blood was cooled down immediately after collection and kept at $4{ }^{\circ} \mathrm{C}$ until processing to minimize in vitro leukocyte and platelet activation. We examined the expression of $\alpha$-subunit of integrin LFA-1 (CD11a), $\beta$-subunit of $\beta$-2 integrins (CD18), ICAM-1 (CD 54) and of lipopolysaccharide receptor (CD14).

The expression of leukocyte molecules was quantified by the flow cytometry (FACSCalibur, Becton - Dickinson, Mountain View, CA, USA) using singlestep staining of whole blood with monoclonal antibodies as described earlier (Stulc et al. 2008). We used the following murine monoclonal antibodies for antigen detection: Anti-CD11a/FITC (clone MEM-25) and anti-
CD18/FITC (clone CLB-LFA-1/1) from Caltag Laboratories, Burlingame, USA, anti-CD54/FITC (clone 84H10) and non-specific control antibody (FITC-labeled, clone 679.1Mc7) from Immunotech, Marseille, France, and anti-CD14/FITC (clone 8G3) from Diaclone SAS, Bresancon, France.

Serum high-sensitivity C-reactive protein (hsCRP) levels were measured by time-resolved amplified cryptate emission technology (TRACE, Kryptor analyser, Cezanne, France) using the kit from Brahms (Hennigsdorf, Germany). Routine laboratory measurements were done using automated analyzer methods. Biochemical markers of renal, liver and skeletal muscle function included serum transaminases, creatinine, creatine kinase and a full blood count.

The results are expressed as a mean \pm SD. For leukocyte molecules, the Mann-Whitney U test was used to compare the differences between the controls and patients; Wilcoxon's paired test was used to compare the values before and after treatment. Differences in the remaining variables were tested by the two-sample or paired $\mathrm{t}$ test as appropriate. All statistical tests are twosided.

\section{Results}

Thirty-two control subjects and 33 patients with type 2 diabetes mellitus were included in the study; all patients completed the entire treatment period. Baseline characteristics of the study groups are shown in Table 1. The average follow-up time was $153 \pm 25$ days. The treatment was well tolerated; neither clinically manifest side effects were noted throughout the study. There was no increase in body weight after the treatment. Serum creatinine was similar in patients and controls, but increased significantly (by $10 \%$ ) after rosiglitazone; the mechanism for this effect of rosiglitazone remains unclear. There were no significant alterations in serum electrolytes, liver tests or blood count.

There was only mild $11 \%$ decrease in blood glucose after the treatment, which was not accompanied by any change in glycated hemoglobin. HDL-cholesterol increased by $17 \%$, but there was also increase in triglycerides (by $25 \%$ ) and in total and LDL-cholesterol (by $13 \%$ and $11 \%$, resp., Table 1 ). 
Table 1. Baseline characteristics and biochemical results of the study subjects.

\begin{tabular}{llll}
\hline & Control subjects & $\begin{array}{l}\text { Patients } \\
\text { before treatment }\end{array}$ & $\begin{array}{l}\text { Patients } \\
\text { after treatment }\end{array}$ \\
\hline Number & 32 & 33 & \\
Sex $($ male/female $)$ & $19 / 13$ & $12 / 21$ & \\
Age $($ years $)$ & $56.4 \pm 8.6$ & $63.8 \pm 10.1 *$ & \\
BMI $\left(\mathrm{kg} . \mathrm{m}^{-2}\right)$ & $25.8 \pm 3.1$ & $29.1 \pm 3.1 *$ & \\
Hypertension & $9(28 \%)$ & $25(76 \%) *$ & \\
Smoking & $10(31 \%)$ & $8(24 \%)$ & $2.75 \pm 0.83 * *$ \\
TC $($ mmol/l) & $5.03 \pm 0.79$ & $4.40 \pm 0.83 *$ & $1.42 \pm 0.29 * *$ \\
LDL-C $(\mathrm{mmol} / \mathrm{l})$ & $2.87 \pm 0.64$ & $2.50 \pm 0.68 *$ & $1.79 \pm 1.20$ \\
HDL-C $(\mathrm{mmol} / \mathrm{l})$ & $1.64 \pm 0.35$ & $1.22 \pm 0.22 *$ & $8.03 \pm 1.93 * *$ \\
TG $($ mmol/l) & $1.15 \pm 0.45$ & $1.52 \pm 0.57 *$ & $5.69 \pm 1.01$ \\
Glucose $(\mathrm{mmol} / \mathrm{l})$ & $5.06 \pm 0.47$ & $9.18 \pm 2.00 *$ & $91.97 \pm 10.96 * *$ \\
HbA $A_{l}$ c $(\%)$ & $3.79 \pm 0.37$ & $5.57 \pm 0.98 *$ & $2.03 \pm 3.16 * *$ \\
Creatinine $(\mu \mathrm{mol} / \mathrm{l})$ & $85.16 \pm 10.68$ & $83.69 \pm 9.23$ & \\
hsCRP $(\mathrm{mg} / \mathrm{l})$ & $1.70 \pm 1.55$ & $4.52 \pm 5.14 *$ & \\
\hline
\end{tabular}

BMI - body mass index, TC - total cholesterol, TG - triglycerides, HDL-C - HDL-cholesterol, LD-C - LDL-cholesterol, HbA ${ }_{1} \mathrm{C}-\mathrm{glycated}$ hemoglobin, hsCRP - high-sensitivity C-reactive protein. Hypertension and smoking are presented as the number (percentage) of patients with the condition. $* p<0.05$ patients vs. controls. $* * p<0.05$ patients before vs. after treatment.

Table 2. Leukocyte expression of activation markers in the study subjects.

\begin{tabular}{llll}
\hline Control subjects & $\begin{array}{l}\text { Patients } \\
\text { before treatment }\end{array}$ & $\begin{array}{l}\text { Patients } \\
\text { after treatment }\end{array}$ \\
\hline $\begin{array}{l}\text { LFA-1 } \\
\text { Lymphocytes }\end{array}$ & & \\
Monocytes & $132.4 \pm 39.8$ & $150.9 \pm 38.3$ & $140.3 \pm 38.9$ \\
Neutrophils & $227.6 \pm 54.8$ & $276.0 \pm 60.0^{*}$ & $242.4 \pm 57.6^{* *}$ \\
CD18 & $57.2 \pm 14.2$ & $65.2 \pm 13.2^{*}$ & $61.9 \pm 13.2$ \\
Lymphocytes & $36.2 \pm 12.3$ & $58.5 \pm 20.6^{*}$ & $39.7 \pm 18.5^{* *}$ \\
Monocytes & $78.5 \pm 28.3$ & $140.9 \pm 49.3^{*}$ & $92.9 \pm 46.2^{* *}$ \\
Neutrophils & $42.3 \pm 18.0$ & $78.7 \pm 28.1^{*}$ & $53.1 \pm 28.6^{* *}$ \\
ICAM-1 & & & $3.7 \pm 1.1$ \\
Lymphocytes & $4.1 \pm 1.0$ & $38.3 \pm 9.5^{*}$ & $32.9 \pm 9.0^{* *}$ \\
Monocytes & $30.7 \pm 8.1$ & $3.9 \pm 1.8$ & $3.4 \pm 1.3$ \\
Neutrophils & $3.2 \pm 1.3$ & & $184.7 \pm 59.0^{* *}$ \\
CDI4 & & $250.0 \pm 73.6^{*}$ & \\
Monocytes & $193.4 \pm 43.7$ & &
\end{tabular}

The expression of leukocyte markers is shown in the arbitrary fluorescence units. CD14 is expressed only on monocytes and was evaluated only on this cell type. $* \mathrm{p}<0.05$ patients vs. controls. ${ }^{* *} \mathrm{p}<0.05$ patients before vs. after treatment.

Leukocyte expression of all molecules examined was at baseline higher in patients compared to controls. Despite only mild decrease in blood glucose, rosiglitazone treatment induced significant decrease of CD18 and CD14 receptor expression and borderline decrease of LFA-1 and ICAM-1 expression (on 
monocytes only, Table 2). There were no significant correlations between the expression of leukocyte surface molecules and glucose levels.

\section{Discussion}

Thiazolidindiones (glitazones) are agonists of nuclear receptors PPAR- $\gamma$. In addition to their glucose lowering action, glitazones exhibit various beneficial effects on the vessel wall. Experimental and clinical studies demonstrated increased endothelium-dependent vasodilation (Walcher et al. 2010), decrease in serum inflammatory molecules (Ryan et al. 2007, Wang et al. 2008) and decreased endothelial expression of adhesion molecules (Sasaki et al. 2005). In this study, we observed increased leukocyte expression of cell adhesion molecules and lipopolysaccharide receptor in patients with type 2 diabetes mellitus, which reversed after the treatment with rosiglitazone. This is the first report of the effect of PPAR- $\gamma$ agonists on these leukocyte activation markers.

Various proatherogenic factors up-regulate the expression of leukocyte adhesion molecules, and numerous studies also demonstrated decrease of their expression after lipid lowering treatment (Huo and Ley 2001, Kostidou et al. 2009, Serrano et al. 2009). Our results extend these observations, demonstrating that antidiabetes therapy by rosiglitazone has similar effects. Adhesion molecules are crucial for leukocyte recruitment into atherosclerotic lesions, and suppression of their expression by rosiglitazone may thus exert beneficial vascular effects.

Unlike cell adhesion molecules, the role of lipopolysaccharide receptor CD14 in atherosclerosis development is less well understood. Together with tolllike receptor TLR4, CD14 is an important part of lipopolysaccharide receptor complex, which plays a prominent role in innate immunity (Palsson-McDermott and O'Neill 2004). Activation of this receptor leads to downstream release of inflammatory cytokines including TNF- $\alpha$ and interleukin-1. CD14 is expressed mainly by monocytes and macrophages, but its soluble form may confer lipopolysaccharide responsiveness to cells that otherwise do not express CD14 (Tapping and Tobias 2000). The role of CD14 in atherogenesis is not straightforward, but it is supposed that monocyte activation by non-specific stimuli could increase inflammatory infiltration of the plaque. In line with this, CD14 C(-260)T polymorphism has been linked to vascular disease in some studies (Hubacek et al. 1999, Unkelbach et al. 1999, Hermann et al. 2012). In addition, oxidized LDL particles were recently shown to upregulate CD14 (Pasini et al. 2007), suggesting the direct activation of lipopolysaccharide receptor pathway by proatherogenic factors. In a clinical setting, and increased expression of CD14 in patients with diabetes was reported in two studies (Fogelstrand et al. 2004, Stulc et al. 2012). Building on this, our results further support the role of diabetes in activating the innate immunity, and demonstrate for the first time the beneficial effects of antidiabetic therapy on this pathway.

The mechanisms whereby rosiglitazone influenced leukocyte function remain to be elucidated. One likely mechanism is the effect through correction of hyperglycemia and insulin resistance. However, rosiglitazone may also exert a direct anti-inflammatory effect, which is mediated through binding to PPAR- $\gamma$ receptors in leukocytes (Hsueh and Law 2001, Lehrke and Lazar 2005, Patel et al. 2006). It is difficult to separate these diverse effects in clinical settings. Our study was not designed to elucidate these mechanisms, but may nevertheless suggest some answers. The improvement in metabolic compensation was only marginal - the moderate improvement in the serum glucose and HDL-cholesterol concentrations was at least partially outweighed by increase in cholesterol and triglycerides. Also, the on-treatment changes in thrombogenic markers did not correlate with changes in blood glucose or lipids. The metabolic effects can therefore hardly explain the beneficial effects of rosiglitazone observed in our study, and some direct mechanisms, independent of its metabolic action, are likely to have contributed to the effect of rosiglitazone on leukocyte function.

While various anti-inflammatory effects of glitazones might appear beneficial, their clinical meaning remains unclear. The meta-analysis of rosiglitazone studies (Bracken 2007) suggested that this drug increases rather than decreases cardiovascular risk, which contrasts with multiple laboratory effects of rosiglitazone, which are all potentially antiatherogenic. On the other hand, pioglitazone was shown to decrease cardiovascular risk (Lincoff et al. 2007), making the picture even more complex. Apparently, the effect on leukocytes and inflammation is only one piece in a mosaic of complex relationship between PPAR- $\gamma$ receptors and cardiovascular disease. Future research is obviously needed to clarify this puzzling issue. 


\section{Conflict of Interest}

There is no conflict of interest.

\section{Acknowledgements}

Supported by grant IGA MZ CR No. NT 12217-5 and by research programme of Charles University Prvouk P25.

\section{References}

BANSILAL S, FARKOUH ME, FUSTER V: Role of insulin resistance and hyperglycemia in the development of atherosclerosis. Am J Cardiol 99: 6B-14B, 2007.

BRACKEN MB: Rosiglitazone and cardiovascular risk. N Engl J Med 357: 937-938, 2007.

CAIMI G, MONTANA M, FERRARA F, PORRETTO F, MUSSO M, CANINO B, LO PRESTI R: Polymorphonuclear leukocyte integrin pattern, at baseline and after activation, in type 2 diabetic subjects with macrovascular complications. Acta Diabetol 40: 14-19, 2003.

FOGELSTRAND L, HULTHE J, HULTÉN LM, WIKLUND O, FAGERBERG B: Monocytic expression of CD14 and CD18, circulating adhesion molecules and inflammatory markers in women with diabetes mellitus and impaired glucose tolerance. Diabetologia 47: 1948-1952, 2004.

HERMANN M, FISCHER D, HOFFMANN MM, GASSER T, QUITZAU K, MEINERTZ T: CRP and CD14 polymorphisms correlate with coronary plaque volume in patients with coronary artery disease - IVUS substudy of the ENCORE trials. Atherosclerosis 220: 172-176, 2012.

HSUEH WA, LAW RE: PPARgamma and atherosclerosis: effects on cell growth and movement. Arterioscler Thromb Vasc Biol 21: 1891-1895, 2001.

HUBACEK JA, ROTHE G, PITHA J, SKODOVA Z, STANEK V, POLEDNE R, SCHMITZ G: C(-260) $\rightarrow$ T polymorphism in the promoter of the CD14 monocyte receptor gene as a risk factor for myocardial infarction. Circulation 99: 3218-3220, 1999.

HUO Y, LEY K: Adhesion molecules and atherogenesis. Acta Physiol Scand 173: 35-43, 2001.

KOSTIDOU E, KOLIAKOS G, KALOYIANNI M: Increased monocyte alphaL, alphaM and beta2 integrin subunits in diabetes mellitus. Clin Biochem 42: 634-640, 2009.

LEHRKE M, LAZAR MA: The many faces of PPARgamma. Cell 123: 993-999, 2005.

LINCOFF AM, WOLSKI K, NICHOLLS SJ, NISSEN SE: Pioglitazone and risk of cardiovascular events in patients with type 2 diabetes mellitus: a meta-analysis of randomized trials. JAMA 298: 1180-1188, 2007.

MORENO PR, FUSTER V: New aspects in the pathogenesis of diabetic atherothrombosis. J Am Coll Cardiol 44: 22932300, 2004.

PALSSON-MCDERMOTT EM, O'NEILL LA: Signal transduction by the lipopolysaccharide receptor, Toll-like receptor-4. Immunology 113: 153-162, 2004.

PASINI AF, ANSELMI M, GARBIN U, FRANCHI E, STRANIERI C, NAVA MC: Enhanced levels of oxidized lowdensity lipoprotein prime monocytes to cytokine overproduction via upregulation of CD14 and toll-like receptor 4 in unstable angina. Arterioscler Thromb Vasc Biol 27: 1991-1997, 2007.

PATEL CB, DE LEMOS JA, WYNE KL, MCGUIRE DK: Thiazolidinediones and risk for atherosclerosis: pleiotropic effects of PPAR gamma agonism. Diab Vasc Dis Res 3: 65-71, 2006.

ROSENFELD ME: Leukocyte recruitment into developing atherosclerotic lesions. Arterioscler Throm Vasc Biol 22: 361-363, 2002.

RYAN KE, MCCANCE DR, POWELL L, MCMAHON R, TRIMBLE ER: Fenofibrate and pioglitazone improve endothelial function and reduce arterial stiffness in obese glucose tolerant men. Atherosclerosis 194: e123e130, 2007.

SASAKI M, JORDAN P, WELBOURNE T, MINAGAR A, JOH T, ITOH M, ELROD JW, ALEXANDER JS: Troglitazone, a PPAR-gamma activator prevents endothelial cell adhesion molecule expression and lymphocyte adhesion mediated by TNF-alpha. BMC Physiol 5: 3, 2005.

SERRANO CV JR, PESARO AE, DE LEMOS JA, RACHED F, SEGRE CA, COMES F: Native LDL-cholesterol mediated monocyte adhesion molecule overexpression is blocked by simvastatin. Cardiovasc Drugs Ther 23: 215-220, 2009. 
STULC T, VRABLIK M, KASALOVA Z, MARINOV I, SVOBODOVA H, CESKA R: Leukocyte and endothelial adhesion molecules in patients with hypercholesterolemia: the effect of atorvastatin treatment. Physiol Res 57: 185-194, 2008.

STULC T, CESKA R, MARINOV I, SKRHA J: The effect of simvastatin and fenofibrate on the expression of leukocyte adhesion molecules and lipopolysaccharide receptor CD14 in type 2 diabetes mellitus. Neuro Endocrinol Lett 33 (Suppl 2): 73-77, 2012.

TAPPING RI, TOBIAS PS: Soluble CD14-mediated cellular responses to lipopolysaccharide. Chemical Immunol 74: 108-121, 2000.

UNKELBACH K, GARDEMANN A, KOSTRZEWA M, PHILIPP M, TILLMANNS H, HABERBOSCH W: A new promoter polymorphism in the gene of lipopolysaccharide receptor CD14 is associated with expired myocardial infarction in patients with low atherosclerotic risk profile. Arterioscler Thromb Vasc Biol 19: 932-938, 1999.

WALCHER T, WALCHER D, HETZEL J, MIELKE C, RAU M, RITTIG K, BALLETSHOFER B, SCHWEDHELM E, HOMBACH V, BÖGER RH, KOENIG W, MARX N: Rapid effect of single-dose rosiglitazone treatment on endothelial function in healthy men with normal glucose tolerance: data from a randomised, placebocontrolled, double-blind study. Diab Vasc Dis Res 7: 178-185, 2010.

WANG G, ZHANG Z, YU J, ZHANG F, HE L, WEI J, MAO J, WANG X: Antidiabetic rosiglitazone reduces soluble intercellular adhesion molecule-1 level in type 2 diabetic patients with coronary artery disease. PPAR Res: article ID 548178, 2008. 